\title{
PENGENDALIAN BIAYA DAN WAKTU DENGAN MENERAPKAN METODE EARNED VALUEANALYSIS (EVA) MENGGUNAKAN SOFTWARE MICROSOFT PROJECT 2007 (STUDI KASUS DI PROYEK PEMBANGUNAN HOTEL BROTHERS 2 SOLO BARU, SUKOHARJO)
}

\author{
Endar Pancaningrum 1), Widi Hartono ${ }^{2)}$, Sugiyarto ${ }^{2)}$ \\ 1) Mahasiswa Fakultas Teknik, Prodi Teknik Sipil, Universitas Sebelas Maret \\ 2) Pengajar Fakultas Teknik, Prodi Teknik Sipil, Universitas Sebelas Maret \\ J1. Ir. Sutami 36A, Surakarta 57126; Telp.0271-634524.Email: pancaningrumendar@gmail.com
}

\begin{abstract}
Abstrak
Untuk mencapai keberhasilan pada sebuah proyek, diperlukan adanya manajemen yang baik yaitu dengan adanya fungsi pengendalian yang dapat mempengaruhi hasil akhir suatu proyek serta dapat meminimalisasi penyimpangan yang terjadi selama proyek berlangsung. Tujuan penelitian ini adalah mengetahui hasil EVA dengan menggunakan Microsoft Project 2007, mengetahui skenario percepatan yang mengalami keterlambatan, dan mengetahui besarnya perkiraan biaya akhir proyek dan waktu yang dibutuhkan untuk menyelesaikan proyek. Metode yang digunakan dalam penelitian ini adalah deskriptif kuantitatif. Analisis data menggunakan metode analitis dan deskriptif. EVA adalah metode pengendalian biaya dan waktu proyek yang mampu menunjukkan indeks kinerja biaya dan jadwal pada setiap pelaporan, sehingga proyek dapat dilihat kemajuan per pelaporan. Analisis data menunjukkan bahwa perhitungan konsep nilai hasil untuk bulan Februari-Maret menunjukkan SPI $<1$ yang artinya penyelenggaraan proyek terlambat, sementara untuk bulan April nilai SPI =1 yang artinya penyelenggaraan proyek tepat waktu. Nilai CPI $>1$ untuk bulan Februari-Maret artinya pengeluaran proyek lebih kecil dari anggaran dan CPI $=1$ untuk bulan April artinya sesuai rencana anggaran biaya. Hasil ETC 3 bulan berturut turut (Februari-April) yaitu Rp. 1.085.123.685, Rp. 357.971.843, Rp. -54.262.692. Hasil EAC 3 bulan berturut turut (Februari-April) yaitu Rp. 21.946.845.982, Rp. 21.980.555.782, Rp. 21.981.362.911. Hasil sisa anggaran berturut-turut selama 3 bulan menunjukkan angka positif berarti anggaran proyek lebih kecil dari rencana anggaran biayanya.
\end{abstract}

Kata kunci : Earned Value Analysis (EVA), Microsoft Project 2007, Pengendalian Biaya, Pengendalian Waktu, Hotel Brothers 2 Solo Baru

\begin{abstract}
The success on the project, there should be good management to control the influences of project's product also minimize deviation on the project. The objective of the research is to know how extent EV A's result by using Microsoft Project 2007, to know the scenario's acceleration which is delayed, and to know the estimation cost of project and time needs to finish the project. The research method used in the reseaerch was a quantitative descriptive. The data analysis was using analitical and descriptive method. EVA is a cost control and project time method which shows cost and time work index of report, so that the progress of project could be seen in per reports. The analysis of data shows that the calculation of value result concept for February - March showed that SPI was less than 1 (SPI<1), means the project was delayed, while in April, SPI was equal to 1 (SPI=1), means the project itself was on time. CPI Value was more than 1 (CPI >1) for Februari - March, it means the project output was less than the estimation cost and CPI was equal to 1 on April, means that the output is proper with the estimation cost. The results of ETC in 3 months (February - April) were 1,085,123,685 IDR, 357,971,843 IDR, and 54,262,692 IDR. The EAC result in 3 months (February - April) were 21,946,845,982 IDR, 21,980,555,782 IDR, and 21,981,362,911 IDR. The remain cost in three months shows in positive number, means the project cost estimation is less than the cost estimation itself.
\end{abstract}

Keywords : Earned Value Analysis (EVA), Microsoft Project 2007, Cost Control, Time Control Brothers 2 Hotel Solo Baru. 


\section{PENDAHULUAN}

Konsep Earned Value Analysis merupakan salah satu metode pengendalian kinerja proyek dari segi biaya dan waktu yang dapat memberikan informasi mengenai posisi kemajuan proyek dalam jangka waktu tertentu serta dapat memperkirakan perkembangan proyek pada periode selanjutnya, yaitu dalam hal biaya dan waktu pelaksanaan proyek Pengendalian dilakukan pada Proyek Pembangunan Hotel Brothers 2 Solo Baru di Sukoharjo, karena pada pelaksanaan proyek mengalami keterlambatan dari jadwal rencana. Pengendalian biaya dan waktu dilakukan agar keterlambatan waktu akhir pelaksanaan dapat dicegah. Pengendalian biaya dan waktu waktu pada proyek ini menggunakan Microsoft project 2007, sehingga terlihat pekerjaan yang berada pada lintasan kritis. Pekerjaan inilah yang nantinya akan dilakukan percepatan proyek, jika proyek mengalami keterlambatan.

\section{TINJAUAN PUSTAKA DAN LANDASAN TEORI}

Proyek

Proyek merupakan suatu kegiatan yang bersifat sementara yang dibatasi oleh waktu dengan mengalokasikan sumber daya tertentu dan menghasilkan suatu produk tertentu yang memiliki mutu yang jelas baik dari segi kuantitas maupun kualitas.

\section{Perencanaan Proyek}

Perencanaan merupakan peramalan masa yang akan datang dan perumusan kegiatan-kegiatan yang akan dilaksanakan untuk mencapai tujuan yang telah ditetapkan. Bentuk dari perencanaan dapat berupa: perencanaan prosedur, perencanaan metode kerja, perencanaan standar pengukuran hasil, perencanaan anggaran biaya, perencanaan program (rencana kegiatan beserta jadwal).

\section{Pengendalian Proyek}

Proses pengendalian adalah usaha yang sistematis untuk menentukan standar yang sesuai dengan sasaran perencanaan, merancang suatu sistem informasi, membandingkan pelaksanaan dengan standar, kemudian mengambil tindakan pembetulan yang diperlukan, agar sumber daya digunakan secara efektif dan efisien dalam rangka pencapaian sasaran.

\section{Pengendalian Biaya dan Waktu}

Tugas pokok yang pertama kali dalam pelaksanaan pengendalian waktu dan biaya adalah merencanakan dengan menganalisis proyek dalam bentuk struktur perincian kegiatan dan anggaran. Kemudian dikembangkan darinya jadwal rencana kerja utama yang dilengkapi dengan rambu-rambu marka atau titik kontrol dan jadwal rencana anggaran pembiayaan. Keduanya merupakan alat pokok untuk mengendalikan faktor-faktor waktu dan biaya dari kinerja proyek.

\section{Konsep Nilai Hasil (Earned Value Analysis)}

Metode "Nilai Hasil" (Earned Value) adalah suatu metode pengendalian yang digunakan untuk mengendalikan biaya dan jadwal proyek secara terpadu. Metode ini memberikan informasi status kinerja proyek pada suatu periode pelaporan dan memberikan informasi prediksi biaya yang dibutuhkan dan waktu untuk penyelesaian seluruh pekerjaan berdasarkan indikator kinerja saat pelaporan (Dewa Ketut Sudarsana, 2008). dalam Konsep nilai hasil dikenal bebrapa parameter untuk mengendalikan biaya proyek antara lain:

a. BCWS (Budgeted Cost for Work Schedule)

BCWS merupakan anggaran biaya yang telah direncanakan berdasarkan jadwal pelaksanaan proyek. Untuk setiap periode yang diinginkan, anggaran biaya pada jadwal pekerjaan dihitung pada level cost account dengan menjumlahkan seluruh anggaran paket pekerjaan.

b. BCWP (Budgeted Cost for Work Performed)

BCWP menunjukkan nilai hasil dari sudut pandang nilai pekerjaan yang telah diselesaikan terhadap anggaran yang disediakan untuk melaksanakan pekerjaan tersebut. Bila angka ACWP dibandingkan dengan BCWP, akan terlihat perbandingan antara biaya yang telah dikeluarkan untuk pekerjaan yang telah terlaksana terhadap biaya yang seharusnya dikeluarkan untuk maksud tersebut. 
c. ACWP (Actual Cost of Work Performed)

ACWP adalah biaya aktual yang dikeluarkan untuk penyelesaian pekerjaan pada periode waktu yang bersangkutan. Biaya aktual didapat dari laporan-laporan dan dikumpulkan pada level cost account periode itu.

\section{Penilaian Kinerja Proyek dengan Konsep Earned Value Analysis}

Penggunaan konsep earned value analysis dalam penilaian kinerja proyek yang terkait dengan penilaian ini adalah Schedule Variance (SV), Cost V ariance (CV), Schedule Performance Index (SPI), Cost Performance Index (CPI), Estimate to Complete (ETC) dan Estimate at Completion (EAC).

1. Penyimpangan Jadwal/Waktu

a. SV (Scheduling V ariance $)=\mathrm{BCWP}-\mathrm{BCWS}$

$\mathrm{SV}>0$, progres aktual $>$ rencana : terjadi percepatan proyek terhadap rencana (schedule underrun).

$\mathrm{SV}<0$, progres aktual < rencana : terjadi keterlambatan proyek terhadap rencana (schedule overrun).

b. SPI (Schedule Performed Index $)=\mathrm{BCWP} / \mathrm{BCWS}$.

SPI $>1$, progres aktual $>$ rencana : terjadi percepatan proyek terhadap rencana (schedule underrun).

$\mathrm{SPI}<1$, progres aktual $<$ rencana $:$ terjadi keterlambatan proyek terhadap rencana (schedule overrun).

2. Penyimpangan Biaya

a. $\mathrm{CV}($ Cost Variance $)=\mathrm{BCWP}-\mathrm{ACWP}$

$\mathrm{CV}>0$, biaya volume aktual $>$ biaya aktual (Cost underrun).

$\mathrm{CV}<0$, biaya volume aktual $<$ biaya aktual (Cost overrun).

b. CPI (Cost Performed Index $)=\mathrm{BCWP} / \mathrm{ACWP}$.

CPI $>0$, biaya volume aktual $>$ biaya aktual (Cost underrun).

CPI $<0$, biaya volume aktual $<$ biaya aktual $($ Cost overrun $)$.

3. Estimate to Complete (ETC)

ETC yaitu jumlah biaya yang diperlukan untuk menyelesaikan proyek berdasarkan data produktivitas terakhir yang dicapai.

$\mathrm{ETC}=(\mathrm{BAC}-\mathrm{BCWP}) / \mathrm{CPI}$

4. Estimate at Completion (EAC).

EAC merupakan besarnya biaya yang akan diserap secara kesecluruhan oleh proyek berdasarkan data produktivitas terakhir yang dicapai.

$\mathrm{EAC}=(\mathrm{ACWP}+\mathrm{ETC})$

\section{Diagram Precedence}

Diagram Precedence disebut juga dengan node diagram atau construction block diagram. Diagram ini merupakan penyempurnaan dari diagram panah, karena diagram panah pada prinsipnya hanya memakai satu jenis hubungan aktivitas yaitu hubungan Akhir - Awal. Pada diagram precedence dapat digambarkan adanya empat hubungan aktivitas yaitu hubungan Awal - Awal (SS), Awal - Akhir (SF), Akhir - Awal (FS), Akhir - Akhir (FF). Selain itu pada diagram precedence aktivitas dummy juga tidak diperlukan lagi sehingga diagram menjadi bersih (Soeharto, 1997).

Ciri-ciri diagram precedence adalah sebagai berikut:

a. Aktivitas tidak dinyatakan sebagai panah melainkan divisualisasikan sebagai node, lingkaran atau kotak.

b. Anak panah atau garis penghubung tidak mempunyai durasi, sehingga pada diagram precedence tidak diperlukan adanya aktivitas dummy.

c. Anak panah dai satu node ke node yang lain menunjukkan hubungan ketergantungan dan urutan aktivitas-aktivitas tersebut. 
Pada Gambar 1 berikut ini merupakan format umum dari sebuah node dalam diagram precedence.

\begin{tabular}{|c|c|c|}
\hline ES & ID & EF \\
\hline \multicolumn{3}{|c|}{ LABEL } \\
\hline LS & D & LF \\
\hline
\end{tabular}

Gambar 1 Node Diagram Precedence

\section{METODE PENELITIAN}

Dalam Penelitian ini, digunakan tiga data proyek sebagai sampel penelitian yaitu time schedule pelaksanaan proyek, rencana anggaran biaya, dan laporan bulan proyek. Penelitian dilakukan pada Proyek Pembanguna Hotel Brothers 2 di Sukoharjo. Waktu peninjauan pada proyek ini yaitu pada bula FebruariApril 2017.

Metode yang digunakan dalam penelitian ini adalah deskriptif kuantitatif, penelitian yang mendeskripsikan kondisi proyek tertentu dengan analisis data yang ada. Analisis data menggunakan metode analitis dan deskriptif.

\section{HASIL DAN PEMBAHASAN}

Data Umum Proyek

Berikut terdapat data administrasi dari proyek tersebut:

Nama Pekerjaan: Proyek Pembangunan Hotel Brothers 2

Lokasi : Solo Baru, Sukoharjo

Luas Bangunan : $\pm 1.543 \mathrm{~m}^{2}$

Waktu Penyelesaian : 1 tahun

Nilai Kontrak : Rp21.981.362.911,00

\section{Hasil Analisis Data}

Hasil dari rekapitulasi indikator-indikator konsep nilai hasil pada perhitungan program Microsoft Project 2007 dapat dilihat pada Tabel 1.

Tabel 1 Rekapitulasi Indikator-Indikator Konsep Nilai Hasil

\begin{tabular}{|c|c|c|c|}
\hline Bulan & $\begin{array}{c}\text { Planned Value } \\
\text { (PV) } \\
\text { BCWS }\end{array}$ & $\begin{array}{c}\text { Earned Value } \\
\text { (EV) } \\
\text { BCWP }\end{array}$ & $\begin{array}{c}\text { Actual Cost (AC) } \\
\text { ACWP }\end{array}$ \\
\hline Februari & Rp. 22.035.625.603 & Rp. 20.894.512.565 & Rp. 20.861.702.297 \\
\hline Maret & Rp. 22.035.625.603 & Rp. 21.623.377.923 & Rp. 21.622.583.939 \\
\hline April & Rp. 22.035.625.603 & Rp. 22.035.625.603 & Rp. 22.035.625.603 \\
\hline
\end{tabular}


Berdasarkan Tabel 2 berikut dapat dilihat hasil perhitungan konsep nilai hasil selama 3 bulan, yaitu:

Tabel 2 Laporan Perhitungan Konsep Nilai Hasil Selama 3 Bulan Mulai dari Bulan Februari-April 2017

\begin{tabular}{|l|l|l|l|}
\hline Indikator & Bulan Februari 2017 & Bulan Maret 2017 & Bulan April 2017 \\
\hline BCWS & Rp. 22.035.625.603 & Rp. 22.035.625.603 & Rp. 22.035.625.603 \\
\hline BCWP & Rp. 20.894.512.565 & Rp. 21.623.377.923 & Rp. 22.035.625.603 \\
\hline ACWP & Rp. 20.861.702.297 & Rp. 21.622.583.939 & Rp. 22.035.625.603 \\
\hline SV & Rp. -1.141 .113 .038 & Rp.-412.247.680 & Rp. 0 \\
\hline CV & Rp. 32.810.268 & Rp. 793.984 & Rp. 0 \\
\hline BV & Rp. 1.173.923.306 & Rp. 413.041.664 & Rp. 0 \\
\hline SPI & 0,9482 & 0,9813 & 1 \\
\hline CPI & 1,0115 & 1,00004 & 1 \\
\hline ETC & Rp. 1.085.143.685 & Rp. 357.971.843 & Rp. -54.262.692 \\
\hline EAC & Rp. 21.946.845.982 & Rp. 21.980.555.782 & Rp. 21.981.362.911 \\
\hline
\end{tabular}

\section{Evaluasi Hasil Perhitungan Konsep Nilai Hasil}

Contoh pelaporan prestasi kerja sampai dengan Bulan Februari 2017, sebagai berikut:

a. Analisa anggaran untuk kegiatan yang dilaksanakan pada Bulan Februari 2017.

BCWS = Rp. 22.035.625.603

BCWP $=$ Rp. 20.894.512.565

ACWP $=$ Rp. 20.861.702.297

Penyimpangan Terhadap Waktu (SV)

Rumus mencari SV adalah:

$\mathrm{SV}=\mathrm{BCWP}-\mathrm{BCWS}$

Jadi untuk pekerjaanpada Bulan Februari 2017:

Diketahui:

$$
\begin{array}{ll}
\text { BCWS } & =\text { Rp. } 22.035 .625 .603 \\
\text { BCWP } & =\text { Rp. } 20.894 .512 .565 \\
\text { SV } & =\text { Rp. 22.035.625.603 - Rp. 20.894.512.565 } \\
& =\text { Rp. }-1.141 .113 .038
\end{array}
$$

Penyimpangan Terhadap Biaya (CV)

Nilai cost variance (CV) setiap periode dapat diperoleh dengan menggunakan rumus, sebagai berikut: $\mathrm{CV}=\mathrm{BCWP}-\mathrm{ACWP}$

Jadi untuk pekerjaan pada Bulan Februari 2017:

Diketahui:

$$
\begin{array}{ll}
\text { BCWP } & =\text { Rp. } 20.894 .512 .565 \\
\text { ACWP } & =\text { Rp. } 20.861 .702 .297 \\
\text { CV } & =\text { Rp. } 20.894 .512 .565-\text { Rp. } 20.861 .702 .297 \\
& =\text { Rp. } 32.810 .268
\end{array}
$$


Indeks Penampilan Jadwal (SPI)

Unuk mendapatkan nilai SPI setiap periode digunakan rumus:

$S P I=\frac{B C W P}{B C W S}$

Jadi untuk pekerjaan pda Bulan Februari 2017:

$S P I=\frac{\text { Rp. 20.894.512.565 }}{\text { Rp. 22.035.625.603 }}=0,9482$

Nilai ini menunjukkan SPI $<1$ artinya penyelenggaraan proyek mengalami keterlambatan dari perencanaan.

Indeks Penampilan Biaya (CPI)

Untuk mendapatkan nilai CPI digunakan rumus:

$C P I=\frac{B C W P}{A C W P}$

Jadi untuk pekerjaan pada Bulan Februari 2017:

$C P I=\frac{\text { Rp. } 20 \cdot 894 \cdot 512.565}{\text { Rp. } 20 \cdot 861 \cdot 702.297}=1,0115$

Nilai ini menunjukkan CPI $>1$, maka artinya pengeluaran lebih kecil dari anggaran.

\section{Prakiraan Biaya dan Waktu Penyelesaian Proyek}

Berikut ini dapat dilihat perkiraan biaya dan perkiraan waktu sampai dengan proyek selesai sesuai rencana, sebagai contoh perkiraan biaya dan waktu sampai dengan Bulan Februari 2017:

a. Perkiraan Biaya Akhir Proyek

Estimate Temporary Cost (ETC)

$E T C=\frac{B A C-B C W P}{C P I}$

$E T C=\frac{\text { Rp. } 21.981 .362 .911-\text { Rp. } 20.894 .512 .565}{1,0015}$

$E T C=\operatorname{Rp} \cdot 1.085 .143 .685$

Estimate At Completion (EAC)

EAC $=\mathrm{ETC}+\mathrm{ACWP}$

$=$ Rp. 1.085.143.685 + Rp. 20.861.702.297

$=$ Rp. 21.946.845.982

Dapat diketahui bahwa biaya yang diperlukan untuk penyelesaian proyek lebih besar dari anggaran yang direncanakan. Dari hasil perhitungan tersebut.

Sisa anggaran $\quad=$ BAC - EAC

$=$ Rp. 21.981.362.911 - Rp. 21.946.845.982

$=$ Rp. 34.516 .929

Hasil sisa anggaran menunjukkan angka negatif berarti anggaran proyek lebih besar dari rencana anggaran biaya.

b. Perkiraan Waktu Penyelesaian Proyek

Total Waktu

$=318$ hari 


\begin{tabular}{|c|c|c|}
\hline \multirow{2}{*}{\multicolumn{2}{|c|}{$\begin{array}{l}\text { Waktu yang telah dilalui } \\
\text { Sisa waktu penyelesaian } \\
\text { Estimate Temporay Schedule (ETS) }\end{array}$}} & \multirow{2}{*}{$\begin{array}{l}=234 \text { hari } \\
=84 \text { hari }\end{array}$} \\
\hline & & \\
\hline & imporay Schedul & \\
\hline ETC & $\begin{array}{l}=\text { Sisa Wakt } \\
=84 / 0,93 \\
=90 \text { hari }\end{array}$ & \\
\hline
\end{tabular}

$$
\begin{aligned}
& \text { Estimate All Schedule (EAS) } \\
& \begin{aligned}
\text { EAS } & =\text { Waktu Selesai }+ \text { ETS } \\
& =234+90 \\
& =324 \text { hari }
\end{aligned}
\end{aligned}
$$

Berdasarkan hasil dari data analisis konsep nilai hasil yang telah dihitung tersebut, dapat kita lihat pada Tabel 3 berikut ini:

Tabel 3 Rekapitulasi Indikator-Indikator Konsep Nilai hasil

\begin{tabular}{|l|l|l|l|}
\hline Indikator & Bulan Februari 2017 & Bulan Maret 2017 & Bulan April 2017 \\
\hline SV & Rp. -1.141 .113 .038 & Rp.-412.247.680 & Rp. 0 \\
\hline CV & Rp. 32.810 .268 & Rp. 793.984 & Rp. 0 \\
\hline BV & Rp. 1.173 .923 .306 & Rp. 413.041.664 & Rp. 0 \\
\hline SPI & 0,9482 & 0,9813 & 1 \\
\hline CPI & 1,0115 & 1,00004 & 1 \\
\hline ETC & Rp. 1.085 .143 .685 & Rp. 357.971.843 & Rp. - 54.262.692 \\
\hline EAC & Rp. 21.946 .845 .982 & Rp. 21.980.555.782 & Rp. 21.981.362.911 \\
\hline VAC & Rp. 34.516 .929 & Rp. 807.129 & Rp. 0 \\
\hline
\end{tabular}

\section{KESIMPULAN}

Berdasarkan hasil penelitian dan pembahasan, maka dapat disimpulkan beberapa hal sebagai berikut:

1. Hasil perhitungan konsep nilai hasil dengan menggunakan Microsoft Project 2007 total biaya yang di habiskan sebesar Rp. 21.981.362.911, laporan bulan Februari 2017 total pengeluaran sebesar Rp. 20.861.702.297, dengan sisa biaya penyelesaian sebesar Rp. 1.085.143.685. Sementara laporan bulan Maret 2017 total pengeluaran sebesar Rp. 21.622.583.939, dengan sisa biaya penyelesaian sebesar Rp. 357.971.843. Laporan bulan April 2017 total pengeluaran sebesar Rp. 22.035.625.603, dengan sisa biaya penyelesaian sebesar Rp. -54.262.692.

2. Dari hasil analisis konsep nilai hasil dapat disimpulkan bahwa laporan bulan Februari 2017 nilai SPI sebesar 0,9482, nilai ini menunjukkan SPI $<1$ artinya penyelenggaraan proyek terlambat dari perencanaan. Indeks penampilan biaya bernilai 1,0115, nilai tersebut menunjukkan CPI $>1$ yang artinya pengeluaran lebih kecil dari anggaran yang direncanakan. Laporan bulan Maret 2017 nilai SPI sebesar 0,9813 , nilai ini menunjukkan SPI $<1$ artinya penyelenggaraan proyek terlambat dari perencanaan. Indeks penampilan biaya bernilai 1,00004, nilai tersebut menunjukkan CPI $>1$ yang artinya pengeluaran lebih kecil dari anggaran yang direncanakan. laporan bulan April 2017 nilai SPI sebesar 1 , nilai ini menunjukkan SPI $=1$ artinya penyelenggaraan proyek sesuai dengan jadwal yang direncanakan. Indeks penampilan biaya bernilai 1 , nilai tersebut menunjukkan CPI $=1$ yang artinya pengeluaran sesuai dengan anggaran biaya yang direncanakan.

3. Perkiraan biaya akhir pada saat penyelesaian proyek yaitu sebesar Rp. 21.981.362.911 dan perkiraan waktu penyelesaian proyek yaitu tanggal 29 Mei 2017. 


\section{DAFTAR PUSTAKA}

[1] Danny Maximilian Pinontoan, Mitchel, Mandagi, R J M, dan Mangare, Jantje. (2015). "Pengendalian Biaya dan Waktu Dengan Metode Analisis Nilai dan Hasil Dengan Microsoft Project 2010". Jurnal Sipil Statik. 3(12), 787-803.

[2] I Gusti Ngurah Oka Suputra. (2011). "Penjadwalan Proyek Dengan Precedence Diagram Method (PDM) dan Ranked Position Weight Method (RPWM)”. Jurnal Ilmiah Teknik Sipil. Vol. 15, No. 1.

[3] Abrar Husen. 2009. "Manajemen Proyek, Perencanaan, Penjadwalan dan Pengendalian Proyek". C.V Andi Offset.Yogyakarta.

[4] Imam Soeharto. 1997. “Manajemen Proyek dari Konseptual sampai Operasional”. Erlangga.Jakarta.

[5] Juliana. (2016). "Analisis Pengendalian Biaya dan Waktu Pada Proyek Konstruksi Dengan Metode Earned Value Management (EVM)". Faktor Exacta. 9(3), 257-265.

[6] Dwi Kartikasari. (2014). "Pengendalian Biaya dan Waktu Dengan Metode Earned Value". Extrapolasi Jurnal Teknik Sipil Untag Surabaya. 7(2), 107-114.

[7] Dewa Ketut Sudarsana. (2008). "Pengendalian Biaya dan Jadual Terpadu Pada Proyek Konstruksi". jurnal Ilmiah Teknik Sipil. Vol. 12, No.2.

[8] Adi Kusrianto. 2008. "Panduan Lengkap Memakai Microsoft Project 2007”. PT. Elex Media Komputindo.Jakarta.

[9] Natasya Stiefani. (2013). "Pengendalian Biaya dan Waktu Dengan Menerapkan Aplikasi Earned Value Analysis Pada Software Microsoft Project 2007”. Skripsi Tidak Diterbitkan. Surakarta. FT UNS.

[10] Budi Witjaksana, dan Samuel Petrik Reresi. (2012). “Analisis Biaya Proyek Dengan Metode Eamed $V$ alue dalam Proses Kinerja”. Extrapolasi Jurnal Teknik Sipil Untag Surabaya. 05(02), 45-56. 